\title{
Lawrence-Lightfoot, Rancière and Gemma: Reconciling the Subject Matter with Research Processes and Outcomes ${ }^{1}$
}

Debbie Qadri

\author{
Victoria University
}

\begin{abstract}
This paper outlines the author's process of reconciling contradictions between the subject matter of her research and the PhD research process and outcomes. It describes a journey which draws on Lawrence-Lightfoot's methodology of portraiture (Lawrence-Lightfoot \& Hoffmann Davis 1997) and the work of Jacques Rancière in considering the ethical relationship between the research outcomes and the public, including the people who were interviewed for the research and the community involved in the subject matter. The paper also explores the author's subsequent commitment to public pedagogical outcomes through seeking to: Prioritise the community most connected to the subject matter and the public as the primary recipients of the research outcomes, create greater respect and acknowledgement for the community members who contributed to the research, create more equitable access and broaden dialogues by using public space to publish research findings..
\end{abstract}

\section{Keywords}

art, arts based research, public art, community art

1 This paper has been developed from its initial presentation at the 2016 Public Pedagogies Institute Conference in its 'paper' form as a long scroll, under the title, Unwelcome Paradoxes: the compulsion to reconcile the subject matter of the research with the vehicle that's carrying it.

Journal of Public Pedagogies, Number 2, 2017

Published by Public Pedagogies Institute: www.publicpedagogies.org

Open Access article distributed under a CC-BY-NC 4.0 license

URL http://jpp.vu.edu.au/

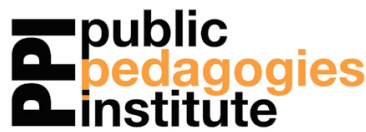




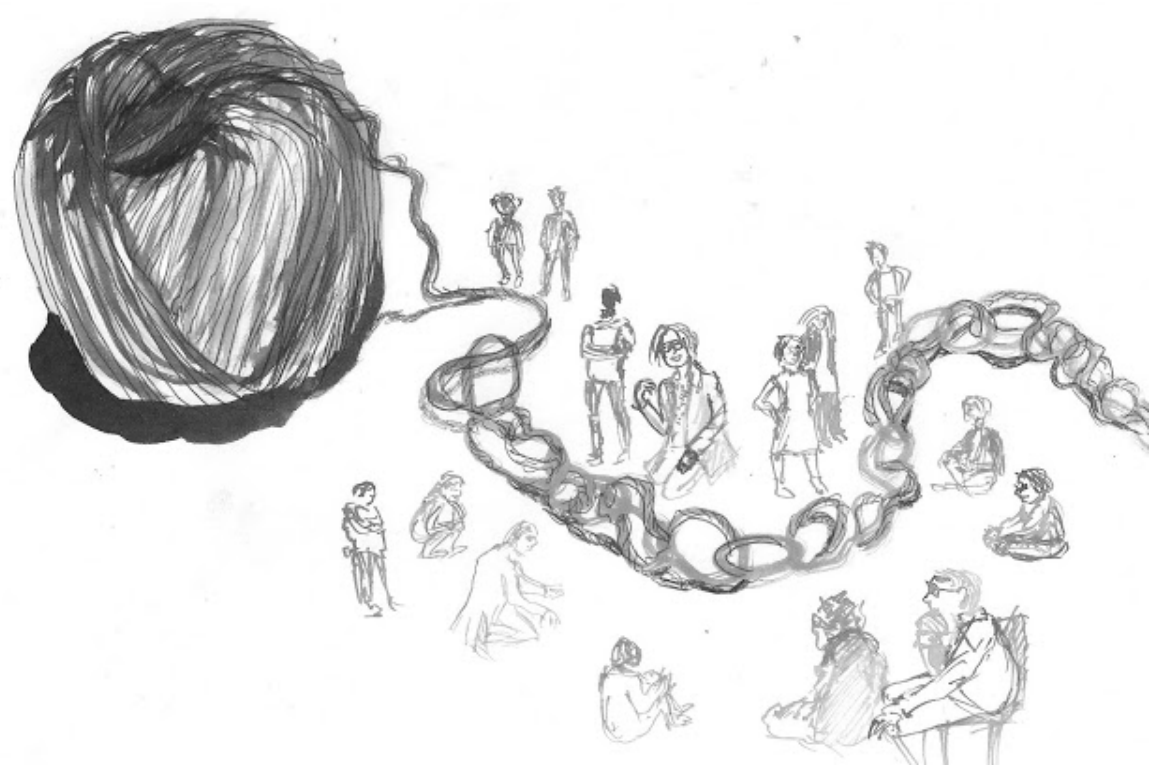

Figure 1: Presenting the 'scroll' at the 2016 Public Pedagogies Institute Annual Conference, Debbie Qadri, 2017.

'disagreement is not only an object of my theorisation. It is also its method' (Rancière 2011, p.2).

\section{Setting the Scene - Position}

I am a PhD student, researching and writing a 'traditional' thesis. I am using Sara Lawrence-Lightfoot's methodology of Portraiture to research two permanent artworks which have been made by communities and my own art practice working as an artist in this field. From the outset Lawrence-Lightfoot's perspective of the interview process as a 'dialogue' (1997 p.3) and its reciprocal nature (Lawrence-Lightfoot \& Hoffmann Davis 1997, p.153-155, 165), resonated with my practice of working with communities.

Very early on I imagined this 'paper' as having two layers (or two parallels) which run one above the other to represent the two parts of my life and how they are linked (fig. 2, Two Layers). The top layer is the $\mathrm{PhD}$ study, (research, conference presentations, articles, thesis) and underneath is the subject matter of the research which is 'permanent public art made by community members'. Within this bottom layer I am also embedded because I work in the field of my subject matter-my current vocation is making permanent artworks with communities mainly schools and kindergartens. These communities hire me to assist them to make permanent artwork. I design and plan with them, run the workshops with participants to make the art and then install it as a larger collaborative artwork.

So I am in both the top and bottom layer. I exist as a researcher of the subject matter but also live within it daily as a worker. For the first two years of my research I continued to work for a living as an artist working with communities, and so my involvement in this field was heavy, taking both substantial time and energy. During this period I worked on twenty seven projects where the community members made the artwork, most of them permanent outdoor ceramic murals.

Initially, I didn't think of my work as very important in terms of the research, it was just a fact of life, separate to study, which had to be done in order to earn a living. But this time-consuming and very physical work in the field affected how I did my research. 


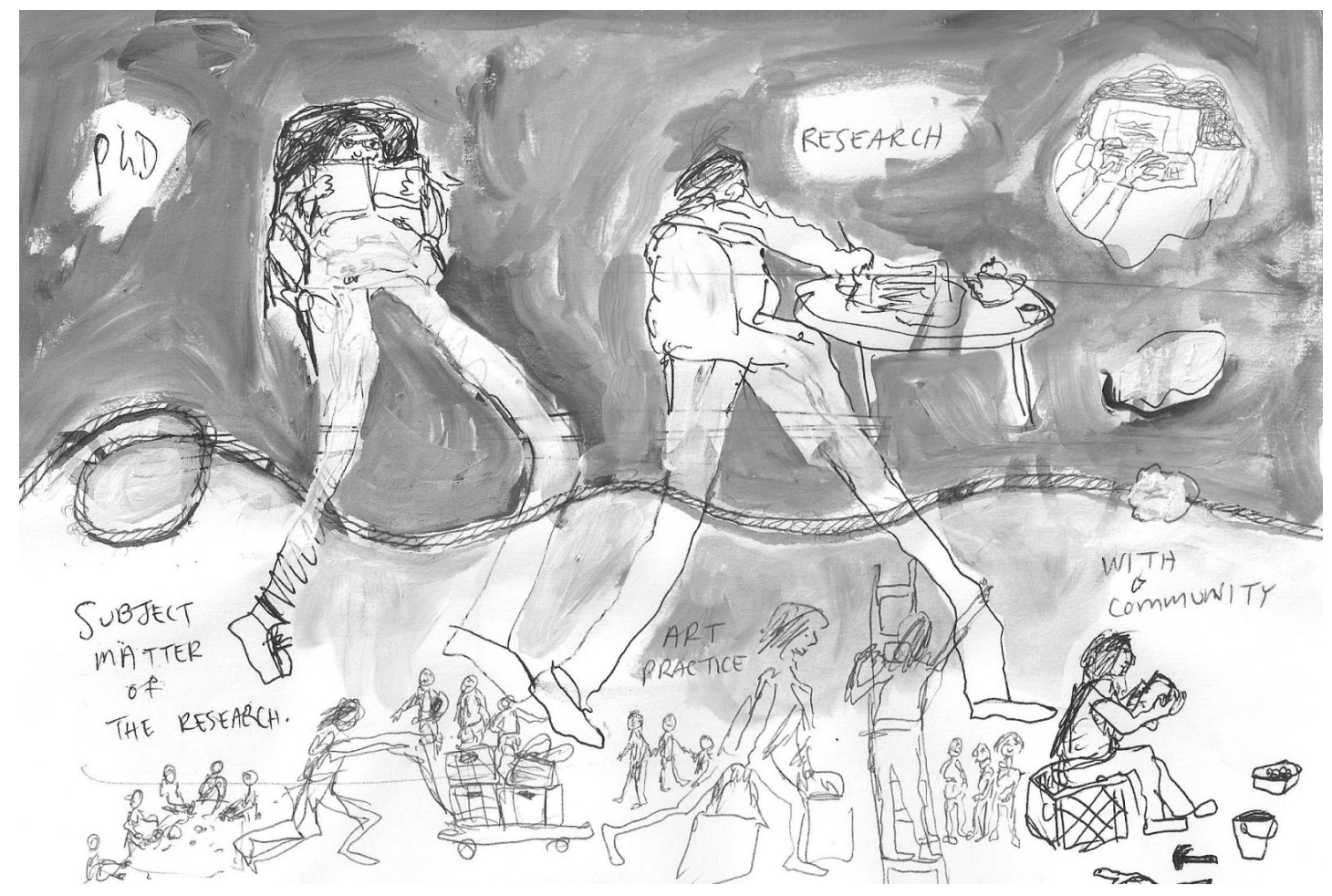

Figure 2: Two layers, Debbie Qadri, 2017.

My reading and writing were inserted into spare moments at work at the sites of the artworks I was making. Throughout the day at different times such as breakfast, tea breaks, and lunch, I would read articles and books, write notes on what I had read and how it related to the work I was doing that day. Often whilst up a ladder, in the workshops or in conversations, ideas came to me, which I wrote down at the time and at the site. This immersion in the subject matter also affected the way I undertook and understood my research.

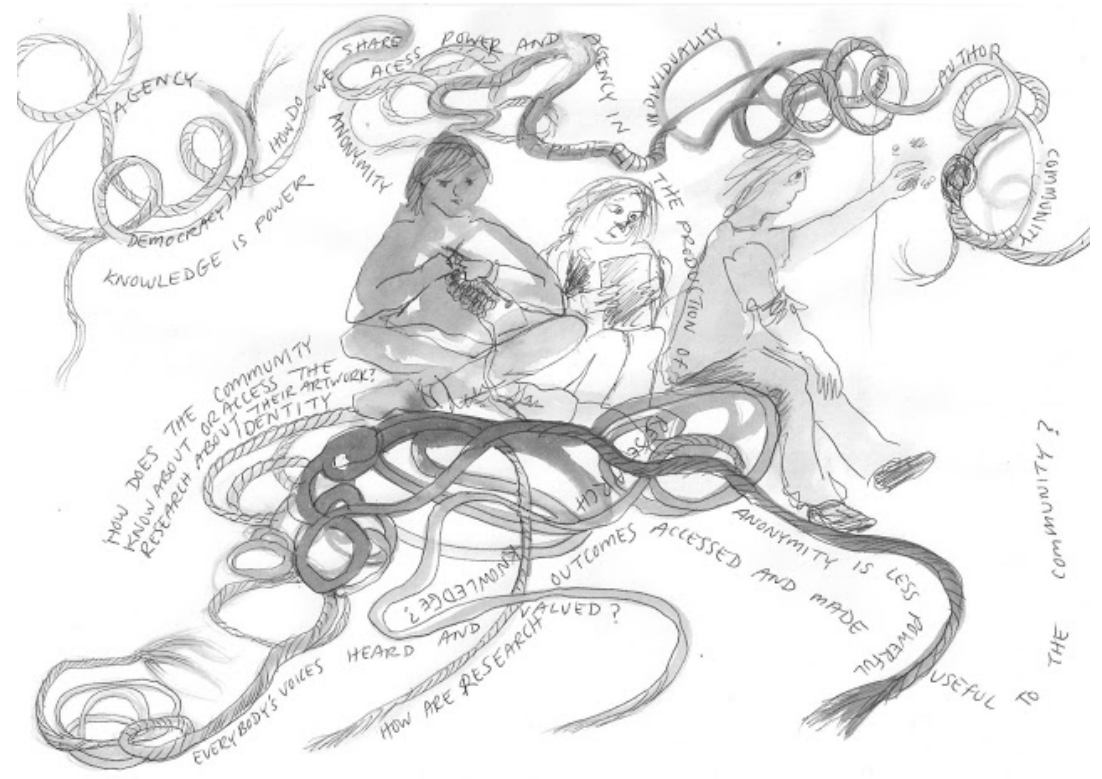

Figure 3: Thinking Whilst Working, Debbie Qadri, 2017. 
Daily, there was an ongoing thinking and sorting of what goes on between these two worlds of art practice and research. Literature was read in light of my actual experience, and I was looking for my experience reflected in what I read. It provided continual reflection from a position inside the subject matter.

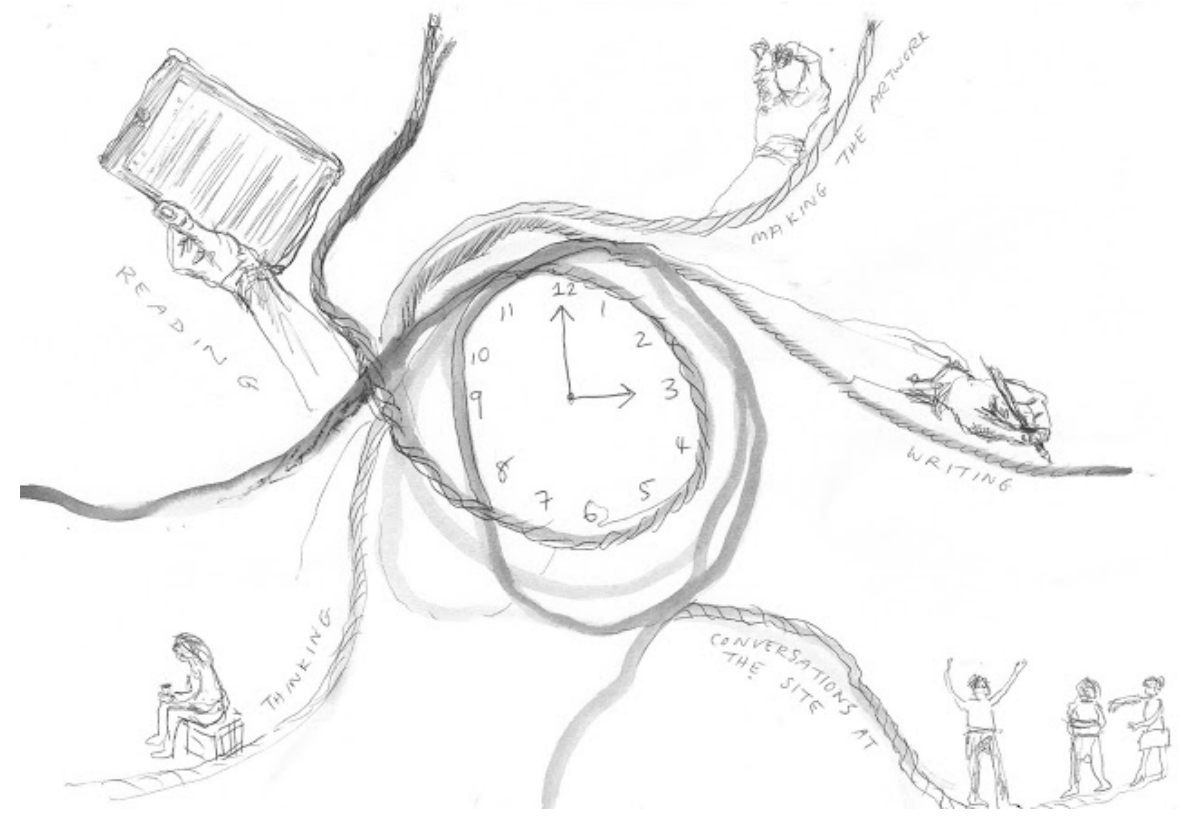

Figure 4: Daily, Debbie Qadri, 2017.

Through this immersive process I became aware of parallels, inconsistencies, contradictions and paradoxes between the research processes and the subject matter of the thesis. There were both differences and similarities between academic practice and community art practice, between ethical engagements with research participants and my engagements with community members when making art. These aspects were confronted daily alongside each other, intertwined and at times knitted. But some threads refused to be woven in. They became untucked, coming loose, sticking out, knotting, clanging, slapping, snarling, getting caught, unravelling into paradoxes, inconsistencies, ironies, and questions.

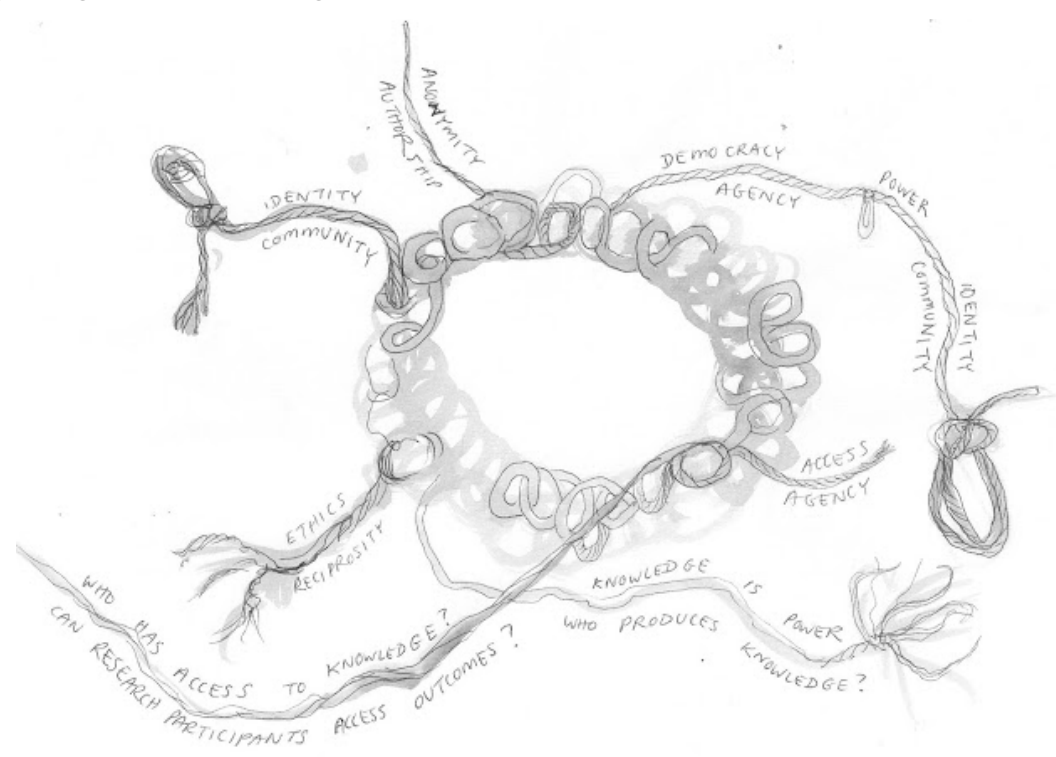

Figure 5 : Untucked, Debbie Qadri, 2017. 


\section{The Change}

How I imagined 'my research', began to change when I involved participants. I realised that my research has to do with a number (actually thousands) of people-it is not just me and the two examiners. When I began to conduct the interviews for my research, I became more aware of possible audiences for my work and the ethics of harvesting knowledge from people and presenting it as my own. The research participants entered my life and the imagined interviews became actual through the receiving of knowledge and stories from real people. They had something to say, and often they had been waiting and wanting to share what they had learnt. They also wanted to be acknowledged by name instead of anonymous. They said they were looking forward to reading the outcomes of the research. I had also under-estimated the depth of knowledge that would be shared with me through the interview process-it provided insights which I would not have been able to gather through other means. I had previously imagined myself the expert and now I was humbled.

\section{Process vs Product/Object - Both in Art and research}

Public art made by a community has to consider two very important but different parts; one is the process of making together collaboratively and the other is the permanent object. A difficult aspect of my work as an artist, is that I have to take control of the artwork to make sure it will survive permanently and that it is also aesthetic so that the community love and respect it. But at the same time, I engage the community participants in making their individual contribution to the final artwork with some choice in what they are doing. This gives them individual ownership of the work as well as being part of the community effort. The process of making the artwork moves either side of a line between choice and control. The artist in control is at the opposite end from community involvement. On the other hand, if community members have more individual creative choice it may entail loss of control of the aesthetic and longevity of the work. A balance is needed.

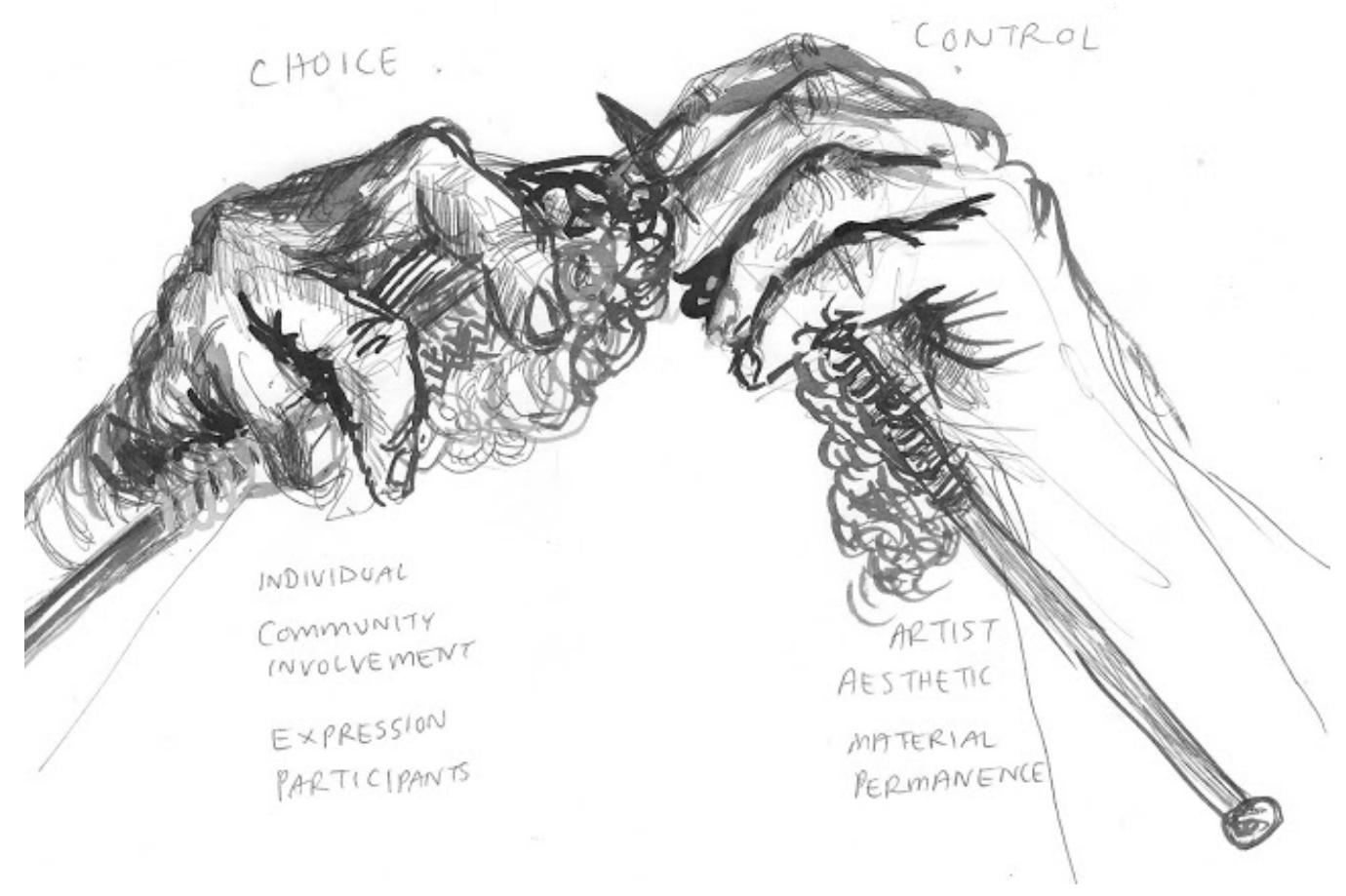

Figure 6: The Balance between Choice and Control, Debbie Qadri, 2017. 
These paradoxes are paralleled in research when you involve participants. I control the subject matter along the lines of my own agenda. The participants in research give their knowledge to the researcher, who then reshapes it and reproduces this knowledge in the world of academia as her own. I began to understand Lawrence-Lightfoot's vision of portraiture as a reciprocal process between researcher and participant (1997, p.153-155, 165).

I felt the need to honour their contributions, to focus on this collaborative effort and acknowledge the participants and the community (who were involved with the artwork) by thinking of them as the most important audience of the outcomes. Lawrence-Lightfoot is concerned that academic texts rarely 'invite dialogue with people in the 'real world', and her concerns are with 'broadening the audience' and 'communicating beyond the walls of academy' (Lawrence-Lightfoot and Hoffman Davis1997, p. 9). I needed to consider how to make the outcomes of the $\mathrm{PhD}$ accessible. In physical form one copy of my $\mathrm{PhD}$ will exist in the university library or in the archives and it will all be available online. It was suggested to me, that the usual thing is to address the wider audience after submitting the thesis, when you turn your research into a book. But I felt it was a strange paradox that the broader public are considered after the research has been written with the examiners in mind. Often after the PhD is completed the research student has limited time and energy left to rewrite the research for a second audience.

If we think about the $\mathrm{PhD}$ as a learning process and a product of knowledge (thesis, award, certificate), the final product of research is a representation of selected parts of the learning process. I began to feel that I needed to consider reciprocity (Harrison et al. 2001, Michel \& Bassinder 2013) with my participants and the communities of the artwork in both the process and the product of my research.

\section{Anonymity, Identity, Power and Authorship}

I noticed that when the interviewees talked about things which seemed off track (things I hadn't thought about), that these were important to the meaning and context of the artwork. Interviewees often provided what Lawrence-Lightfoot calls 'divergent' (1997, p.192) or 'deviant voices' (1997, p.193) which when pursued, led deeper into the meaning of the artwork.

There was one conversation from the research interviews that lodged in my head and sat heavily in my chest. I was being told that in the artwork, people were discouraged from taking credit for their contribution-those who wanted to jump on the bandwagon for self-gain were given short shrift. The conversation then turned towards research, and I was reminded that sometimes researchers come into communities, gather what they need, then leave and publish the work, taking all the credit. This conversation strikes at the heart of the dilemma between the artist taking credit for their work, or acknowledging the community as the makers. The very act of making an artwork with the community, with a group of non-artists, is to say no to the 'self'. Alternatively, if the artist takes credit, the community input is valued less. A point of balance which acknowledges the contribution of everyone needs to be found.

Actually the title of this paper, 'Lawrence- Lightfoot, Rancière and Gemma: Reconciling the Subject Matter with the Academic Thesis, Research Process and Outcomes', has been shortened. It was meant to be: 'Lawrence-Lightfoot, Rancière, Gemma, Sally, Karen, Tariq, Ron, Helen, Alexis, Fatima, Michael and Sonja: Reconciling the Subject Matter with the Academic Thesis, Research Process and Outcomes'.

I wanted to acknowledge all of the research participants in the title, because I felt that they had influenced my thinking, as much as the academic theorists. The research 
participants had provided me with their experiences, insights and knowledge that could be developed into theory. My participants also had something to say and they wanted to be acknowledged.

However, when I typed up the longer inclusive title, I noticed that I had used the surnames for academics and the given names of my interviewees, thus accidentally creating a hierarchy. I think this happened because when working with the community it is a common practice to use the first names of people and children when exhibiting or publishing. This is a practice that sits between acknowledging the participant and protecting their identity. It is also a practice that compromises acknowledgement by removing identity and by using the given name instead of the surname, it also removes the legal and authoritative aspects. (Ironically) in this paper, in order to not link any of the research participants with possible harm in a paper which is not part of the case studies, I have used fake names. It exemplifies the complexity of the field of reciprocity and acknowledgement, where working out how to be ethical might sometimes prove difficult given circumstances of the time, materials, space and traditional methods in research and publishing. Working towards reciprocity also, 'highlights the tensions in representation, the legitimisation of knowledge and the power distance between and among researchers and participants' (Trainor and Bouchard 2013, p.989, referencing Fine et al. 2003).

Traditionally the researcher is named and the participants in the research (who contributed knowledge), often remain anonymous in order to be protected from possible harm. Researchers and artists have their surnames attached clearly to the work, because authorship is important for their reputation and ongoing careers through which they may make their living. It was a disconcerting paradox. My own dilemma as an artist was whether to not have my name anywhere, thus making the artwork democratic, or to leave a permanent mark of authorship so that the outcome could be attributed to me as part of my oeuvre. As an artist I do a lot of the creative work, but the community always contribute intellectually and creatively. The artwork arises out of the community needs and desires and wouldn't exist otherwise. Conversely, the artist/author's name is often attached to the work because it lends credence and value to the final piece.

Disconcertingly I began to feel that I was engaged in some sort of collaborative research with my participants, even though my interview was limited to an hour with each of the participants, my research was in essence a dialogue with a community of people who all had a stake in the artwork, a stake in the research which stemmed from it and also in the outcomes of the research. Trainor and Bouchard (2013, p.986) explain that, 'participants devote their time, effort, experiences and wisdom to inform and shape the researcher's study'. The participants in my own research had provided me with the knowledge, new learning and understandings of the subject that couldn't be gleaned any other way. I needed to explore this idea of reciprocity within my research methodology, and work out in which ways it could be incorporated into my research, including the involvement of participants, the wider community, feedback strategies and the dissemination of research outcomes (Freshwater 2017, Harrison et al. 2001, Michel \& Bassinder 2013, Toombs 2016, Trainor \& Bouchard 2013).

\section{Reciprocity}

Similarly, when I work with communities to make artworks, they give their time and creative effort to the project and trust me to complete my role. One of my commitments is to get the artwork completed and installed into public space (often no mean feat), and to make it aesthetic. This exchange or reciprocity of working together, making, and com- 
mitment to complete the final work as an honouring of the participants, is a common theme which moved across into (and paralleled) my practice of research. In both practices I felt the importance of a reciprocity of communication, time and knowledge given by the community in exchange for outcomes.

\section{The Audience-Examiners or the Community and the Public?}

In doing a PhD we often begin with the self. Amongst many reasons to embark on a higher degree by research, perhaps we want the challenge of the highest qualification, it might assist our career, or we are drawn to research an area of interest. It is usually a personal decision and the research subject matter is something you are interested in. You are usually doing it alone, it will be your life for three or more years and you will not be paid. ${ }^{2}$

Writing the thesis 'for the examiners' is not a perspective that sits well with ideas of equity, and communication of research results to a broad audience. An important aspect of the methodology of portraiture is that it addresses a wider audience than academics:

'With its focus on narrative, with its use of metaphor and symbol, portraiture intends to address wider, more eclectic audiences, The attempt is to move beyond academy's inner circle, to speak in a language that is not coded or exclusive, and to develop texts that will seduce the readers into thinking more deeply about issues that concern them.' (Lawrence -Lightfoot \& Hoffman-Davis 1997, p.10)

Thinking about these words of Lawrence-Lightfoot I hone in on the words 'wider', 'eclectic audiences' and also the phrase, 'think deeply about issues that concern them'. Previous to the interviews I hadn't even imagined that the research participants would have their own theories and concerns about the subject matter. I was surprised and elated at the discovery of other like-minded people who were engaged with what it meant to make public art with community. I had discovered a very important audience for my work, and they were waiting to see what I would write.

Keen and Todres' (2007) exploration into ways of disseminating research outcomes beyond the thesis has arisen from their concerns about the lack of dissemination of the knowledge gained from qualitative research and a need for more ethical outcomes for research; 'Though the number of qualitative projects increases year on year, the implications of this work appear to remain on shelves and have little impact on practice, research, policy or citizens (Keen \& Todres 2007, p.2). Likewise Lightfoot-Lawrence (1997, p. 9-10) finds issue with the fact that academic documents are read by a small audience of people in the same disciplinary field and Trainor and Bouchard (2013) acknowledge that the 'demands of the field', shape how research is presented and disseminated.

2 There are many exceptions to this in other research areas, such as science and sport where a PhD may form a part of the research for a much larger study. 


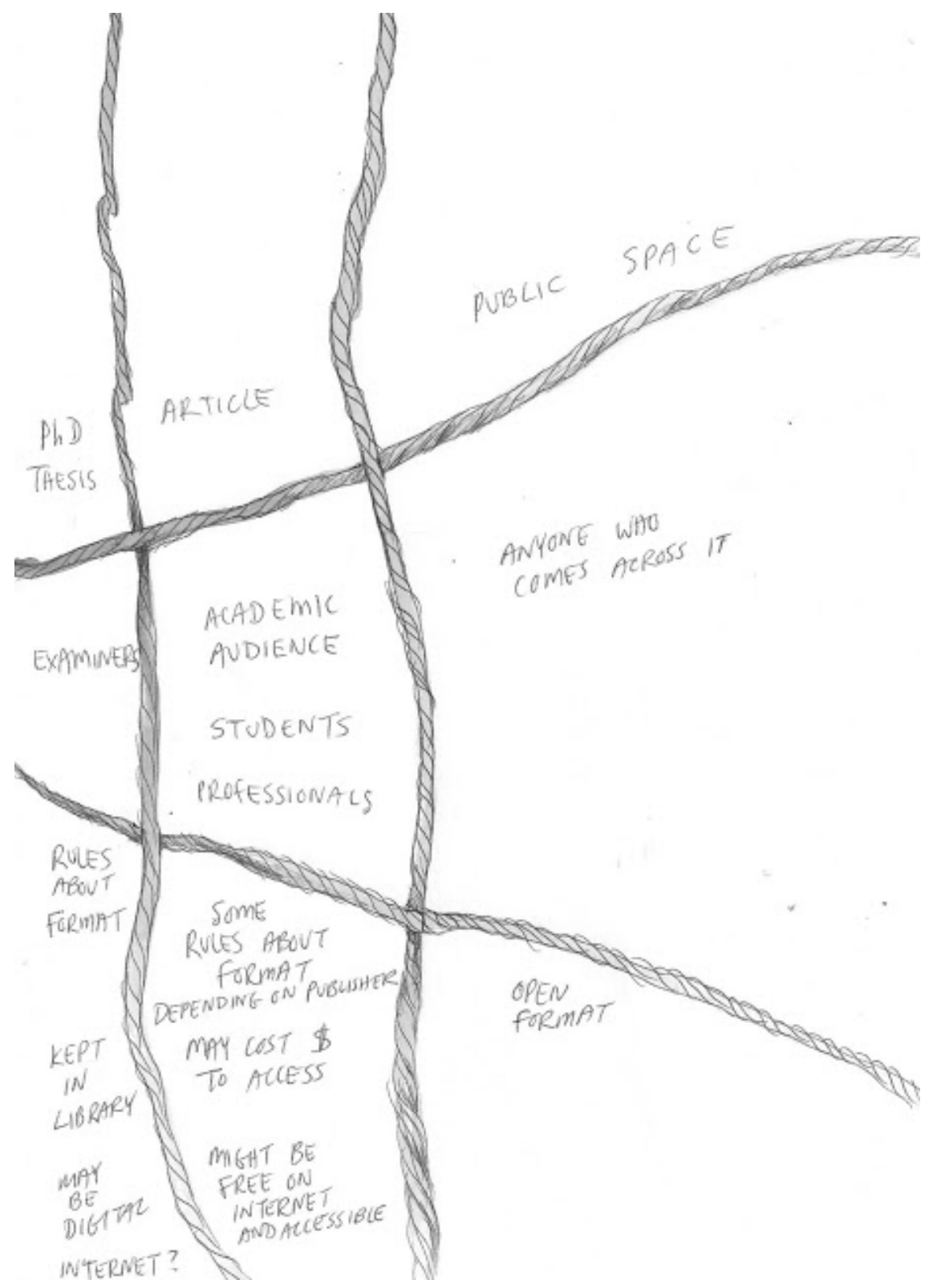

Figure 7: Audience and Outcomes, Debbie Qadri, 2017.

Late in December 2016 I met with the Victoria University archivists, who had been collecting some of the artworks from one of my projects. As they showed me around the archives (which were in a basement, unknown and largely inaccessible to most people), I encountered, housed along a long wall of shelves, an archive of theses. This very real encounter of knowledge which took years to write, (of which only three copies were usually printed) stored in a basement and hardly accessed was another poignant moment for me.

During my research I often looked for documents on the internet before I accessed the journal portal through the library. Journal articles are often difficult to access if you are not a member of a research library and they often cost money. This process made me aware of the inequitable access to knowledge and the importance of placing my research in accessible places which are also financially free. 


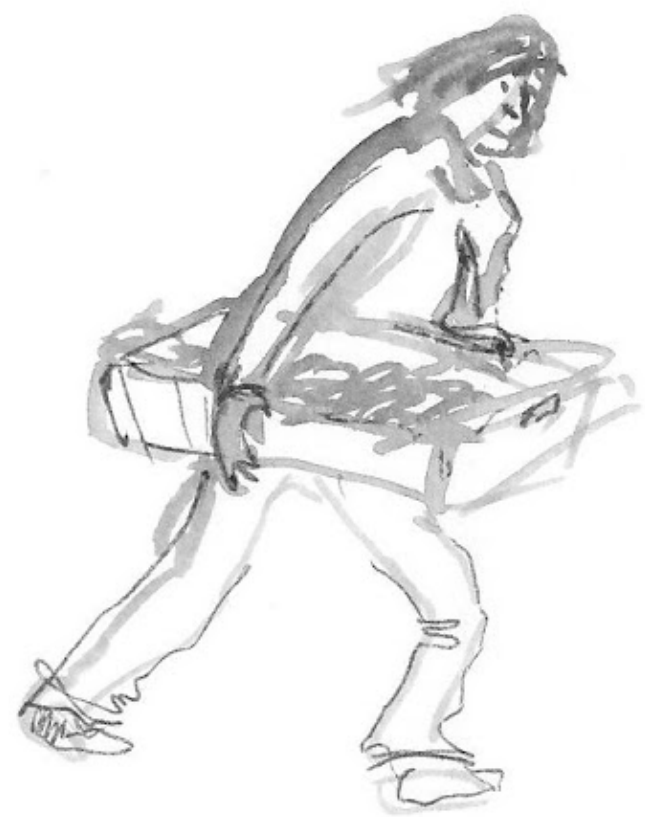

Figure 8: Carrying (a), Debbie Qadri, 2017.

\section{Carrying}

In the process of making permanent artworks with communities, I actually carry the weight of the project many times. It is heavy-being clay and tiles and cement. The weight of the project is sometimes carried home so that I can dry the ceramic work, then carried to the car, then carried into the kiln room, then carried back to the car, then carried out of the car into the house where it is glazed, then carried back to the car, then carried from car to kiln room and into the kiln, then carried back out again to the car, then carried home again and so on, then eventually carried to the site of installation. The precious artwork may weigh between 15 and 600 kilos (with the addition of tiles for the background, glue and grout) and I will generally carry the full weight of the artwork at least twelve times.

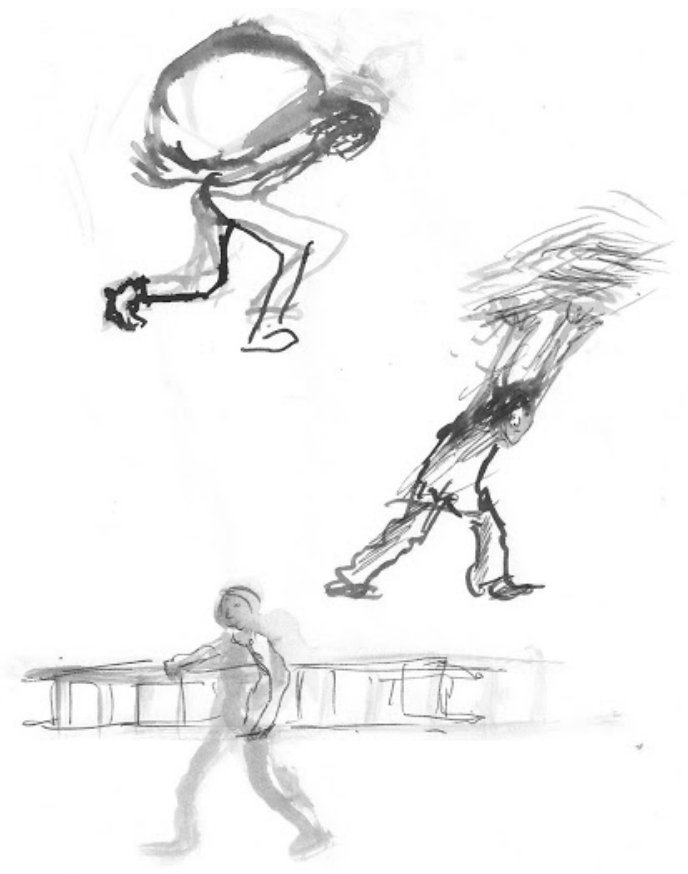

Figure 9: Carrying (b), Debbie Qadri, 2017. 
I also carry it in my head (mentally) shifting the pieces around, inserting coloured backgrounds of broken tile. Thinking, how it will work? What will go where? How will I bring out the individual artworks into their best light? I also carry a burden. The artwork that each person made must be looked after very carefully, it must be transported and fired with care, then it must be placed into the larger artwork with care so that it is part of the final collaborative piece but also stands out as an artwork by an individual. These actions form part of my responsibility and role.

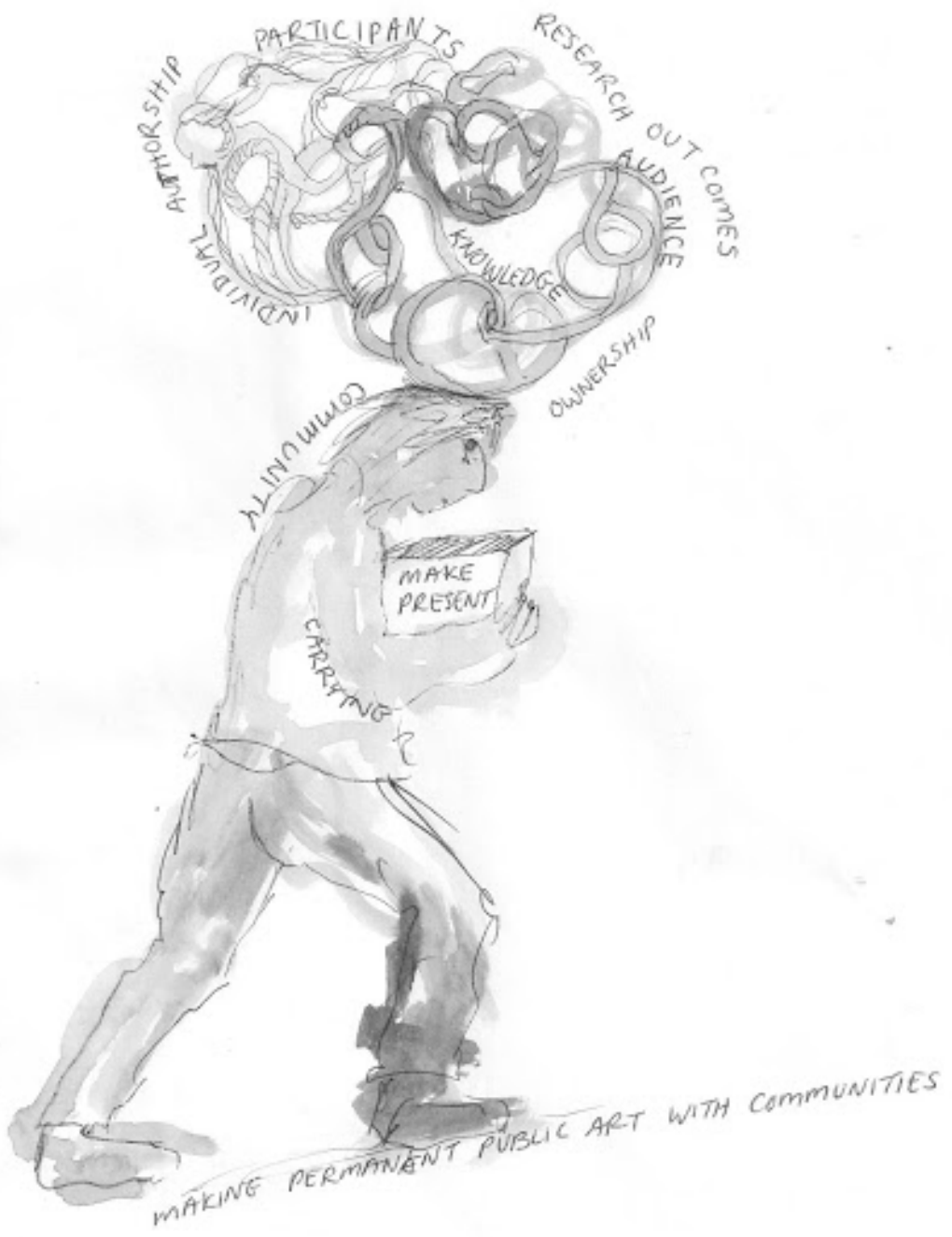

Figure 10: Carrying and Thinking, Debbie Qadri, 2017.

The thesis research, is likewise carried along by the practice of community members making public art. The PhD could be imagined as a parasite, being carried on the surface of my practice, the artworks that I research and the community of people involved with the artwork that I am researching. The research is also carried by the literature that other people have written. A network of information from various sources, holds up and supports the various narratives and arguments I write. As I involve people in my research, and participants tell me of their experiences, the research is propelled further along, they give it walking legs. 


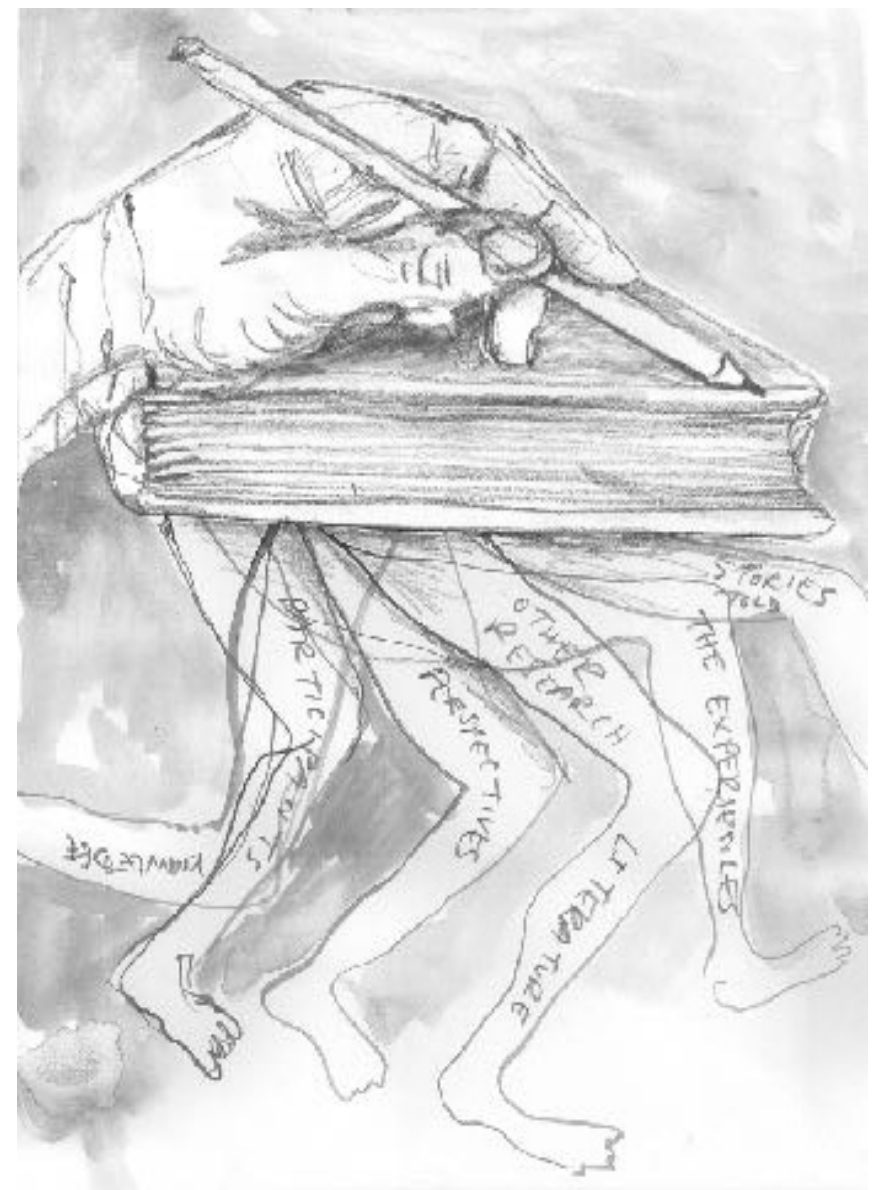

Figure 11: Walking Legs, Debbie Qadri, 2017.

\section{The Up-Ending}

My ethical dilemma provoked an up-ending of the positions of research and the subject-matter. In an 'up-ending' movement, I exchange the places of the research and the practice. I move my practice of working with communities and the subject matter of the research - 'permanent public art made by community members' - onto the top layer, as a priority, above the research outcomes.

The research is no longer supported and carried by the practice, but instead, the research becomes the vehicle for the practice. The $\mathrm{PhD}$ is the vehicle, that runs underneath (carrying) the subject matter. It drives it, holds it up, it runs around collecting the knowledge (the perspectives and experiences of those involved) and takes it somewhere.

When Lawrence-Lightfoot says, "The portraits are designed to capture the richness, complexity, and dimensionality of human experience in social and cultural context, conveying the perspectives of the people who are negotiating those experiences' (Lawrence-Lightfoot \& Hoffmann Davis 1997, p.3). I can see the word conveying as not only in terms of communication but conveying as in carrying and giving it wheels to travel. Like Patricia Leavy's 'representational vehicles' in arts-based research, where the research outcomes are used as vehicles for social justice (Leavy 2009, p.18). I want the research to give the subject matter legs to stand on and wheels to travel. 


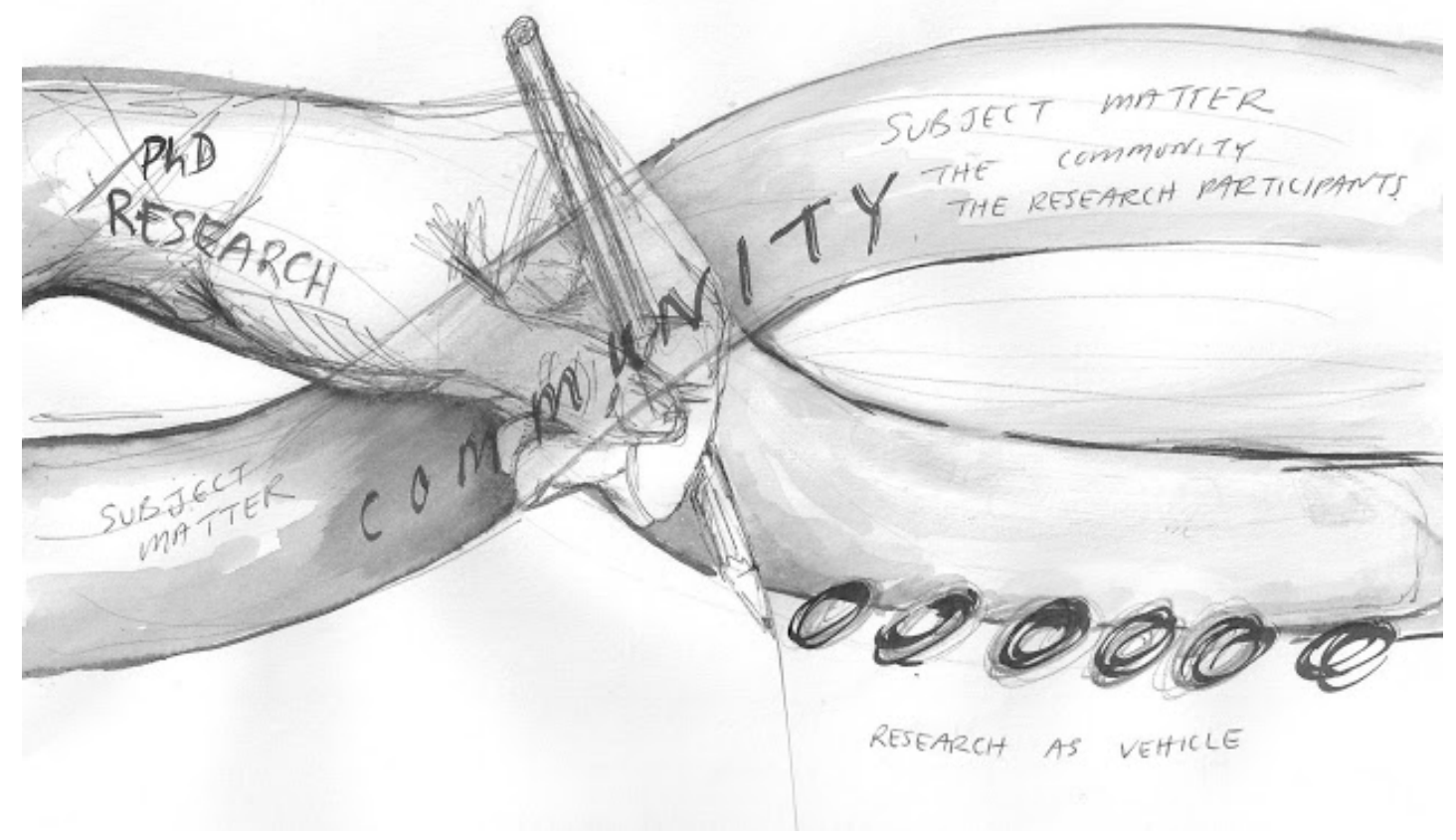

Figure 12: The Up-Ending, Debbie Qadri, 2017.

\section{Using the Power of Research to Carry the Subject Forward}

Research can be used to shed light on the subject matter, to tell the story of what is good about the subject matter (Lawrence-Lightfoot \& Hoffmann Davis1997, p.9). It has the possibilities of carting the subject matter around and depositing it in places. Like a float in a parade it travels and celebrates the story of community made permanent public art. The up-ending is an opposite movement, in that whilst the subject matter of the research was previously seen as something that the research uses, in an opposite situation, the subject matter uses the research. Research can be utilised to give the subject matter strength and take the artwork where it cannot go by itself. This vision of the up-ending provides greater room for a reciprocity between research and subject matter, as well as a reciprocity between the researcher and the people of the communities involved in the subject matter of the research.

\section{Up-Ending Hierarchies}

Jacques Rancière interrogates the division between those who possess knowledge (the teachers) and those who need to be taught (the ignorant) (Ross, in, Rancière 1991, p. xvii). In opposition, to these beliefs Rancière's work follows the 'implications of the idea that human beings are equal in all respects' (Deranty 2010, p.3), 'not just in legal or moral terms, but also in terms of their intellectual and discursive capabilities' (Deranty 2010, p.6). In The Ignorant Schoolmaster, Rancière tells the story of Jacotot, who learnt by experience that his students did not need him to teach them, on the contrary, as Jacotot concludes; 'I must teach you that I have nothing to teach you' (Rancière, 1991, p15).

In Rancière's idea of the 'distribution of the sensible', there is an implicit set of rules and conventions which distribute the roles in society and the forms of exclusion that operate within it. It sets divisions between what is sayable and unsayable, audible and inaudible (Sayers 2016). He identifies the separation between those who create knowledge and those 
who are the audience for it and uses his role as researcher, to work on closing this separation. Rancière follows the implications that everyone has capacity for knowledge and learning. This is similar to my philosophy of making artworks with communities-I raise their creative work up to say, 'Everyone can make art and their art is valuable'.

In much the same way that the theatre renders the audience passive (Rancière 2009, p. 274), an artwork creates an audience, and research creates participants and readers. This is similar to the process that takes place in the pedagogical relationship between the teacher and the student, or in Rancière's terms, the 'schoolmaster' and the 'ignorant'. This hierarchical structure needs to be upended by action. Action, like Rancière's idea of a theatre without spectators, 'where those in attendance... become active participants as opposed to passive voyeurs' (Rancière, 2009, p.4)-active in participating in the construction of art and the construction of knowledge. Rancière claims that 'Equality is not given, nor is it claimed; it is practiced, it is verified' (1991, p.137), that it is not an 'end' but a 'point of departure' (1991, p.138).

\begin{tabular}{|c|c|c|c|}
\hline Action & Process & Towards & Object \\
\hline before & making & action & after \\
\hline context & action & dissemination & effect \\
\hline need & action & displaying & the remains of the action \\
\hline researcher & producer & presenter & presentation \\
\hline question & research & write-up & \\
\hline planning & process & & artwork \\
\hline why & expression & audience & thesis \\
\hline evidence & create & show & \\
\hline
\end{tabular}

\section{Creating More Equitable Access and Broadening Dialogues by using Public Space to Publish Research Findings}

Keen and Todres (2007, p.4) suggest using strategies such as; 'Tailoring approaches to the audience in terms of the content, message and mediums, paying attention to the source of the message and enabling active discussion of research findings'. Leavy (2009, p.18) also suggests that 'ascertaining information about audience response may... serve as another validity check (as well as a data source)' and 'postviewing dialogue with the audience can enable the researcher to gauge the emotional effect of their work, to ensure that no harm was done and how the audience experienced it. Others considering how 'reciprocity' might play out in research outcomes for non-academic audiences include; Stevenson \& Holloway 2016, Trainor \& Bouchard 2013, Michel \& Bassinder 2013.

In paying attention to the source of 'the message' or the knowledge, I also give attention to the research participants and the communities of the artworks. Lawrence-Lightfoot (1997, p.3) speaks about the portraitist and the subject, 'each one participating in the drawing of the image' as something 'crucial to success and authenticity'. I felt that the relationship with the community of the subject (the artwork) should be extended beyond the six interviews that I had planned, and feedback on drafts. Organising to meet again (formally or informally) with the research participants and the wider community to discuss the research outcomes, can contribute more data, increased validity of the research outcomes, greater reciprocity and also the conveyance to a broader community of the knowledge gained through the research (Keen and Todres 2007, Leavy 2009, Michel \& Bassinder 2013). With this in mind, my plans changed to include presentations and 
discussions of the research findings, with both the research participants and also the community involved in the artwork that I was researching.

\section{Voice}

I also aim to give 'voice' to the research participants in order to value and acknowledge their individual contributions. Many acknowledge the feminist movement's effect, in its focus on power dynamics in the research process and critical discourse about related issues such as voice, authority, reciprocity, representation and reflexivity (Leavy 2009, p.7-8, Harrison et al. 2001, p.323). Leavy also notes that the social justice movements of the 1960s and 1970s have influenced the theoretical perspectives of many researchers across disciplines, many of whom 'seek to give voice to those who have been marginalised as a result of their race, ethnicity, gender, sexual orientation, nationality, religion, disability or other factors (2009, p.13). Stevenson \& Holloway (2016), suggest that 'the challenge of amplifying participant's voices can be addressed using alternative media and methods'.

\section{Public Pedagogy}

I envisage the idea of 'public pedagogy' as teaching and learning in public space, outside of formal educational settings. I see public pedagogy as a site of potential-a place in which to create more equitable access to research outcomes. I can place the research into public space, both physically and digitally. By placing the research into public space I make it more accessible, broaden the dialogue about the research subject and engage the public with research outcomes.

I am particularly interested in the parallels and relationships between art in public space and research in public space.

Public art plays a role in learning, teaching and sharing knowledge in public space (Qadri 2016, p. 39). Public art (made by artists or community members) has a role to play in areas of democracy and equity (Phillips 1995, p.60, Mouffe 2008, p.13, Qadri 2016, p.37). As Rosalyn Deutsche (1988, p.269) argues ' ...supporting things that are public promotes the survival and extension of democratic culture'. Judith Baca's vision is that public art, 'could have a function for the community and even provide a venue for their voices' (1995, p.135). Public pedagogy, as it forms in public spaces, cultural places and discourses (Burdick \& Sandlin 2010, p.116), is a potential field of practice where research outcomes can be presented to the community.

Public art made by community also challenges how public art is imagined and the dominant discourse of public art (Qadri 2016). Neither of the artworks that I researched evolved from the usual commissioning processes of public art, instead they arose from communities that were not in the art-profession. In considering the output of research outcomes, we may need to think beyond the usual structures and practices of research of journals, thesis and conferences as all of these take place in spaces largely inaccessible to the general public. Hard-copy theses need to be accessed at the library, journal access may need to be paid for and conferences are expensive to attend.

I imagine public pedagogy to be several things which includes, the ideas that visual art in public space presents, community members making art in public space (a process involving, sharing and expressing knowledge) and creating and placing knowledge beyond formal educational spaces (digital and physical). Placing research into public space of the community could involve the whole process of research-analysis, process, write up and final product-thinking foremost about the community from whom the research was gathered and whom the research is concerned with. This would acknowledge the community 
as both pedagogues who give knowledge to the researcher and as public recipients of the researcher's work. A giving backwards and forwards, reciprocally.

\section{Who is an Artist? Who has Knowledge? Who can Speak?}

I feel a need to engage in academic writing because I feel it has a role to play in discourse. It is a type of power, that can affect public art culture, policies and practice. Jake Burdick and Jennifer Sandlin (2010, p.117) raise the issue that; 'there has been little discussion of the problematic role of the researcher, who is likely closely affiliated with the institution - and the tools/means/languages she uses to query, analyse, and re/create these public spaces'. I, like others, engage in these worlds of art and academia, but reserve skepticism of the discourses of value and hierarchical divisions that they are built on (Hawkins p. xix, Foucault 1981, p.53-54, Toombs 2016).

Sandlin and Burdick (2010, p.117) suggest that the academic discursive space is limited by what is 'an already-known construct of how education looks and feels', which may pose problems 'for researchers interested in the pedagogies beyond and between institutional boundaries'. Research generally is 'associated with schools and schooling and to the standards that produce the boundaries of acceptability within the field'-such as the review process for scholarly publications and presentations (Sandlin \& Burdick (2010, p.117). Foucault (1981, p.55) says that 'the will to truth, like other systems of exclusion, rests on an institutional support: it is both reinforced and renewed... by the way knowledge is put to work, valorised, distributed and in a sense attributed in a society'.

'What after all is an education system, other than a ritualisation of speech, a qualification, and a fixing of the roles for speaking subjects, the constitution of doctrinal groups, however diffuse, a distribution and an appropriation of discourse with all its powers and knowledges' (Foucault 1981, p.64).

I feel like more of a game player, in that we must work within the worlds and cultures that we find ourselves in, by participating but also challenging. The backbone of my art practice with communities is a belief that everyone can make good art, and that everyone has something to valuable to say. This is echoed in Rancière's basic premise that, 'everybody thinks, everybody speaks' (Hallward 2005, p.26).

'.. it is about recognising that there are not two levels of intelligence, that any human work of art is the practice of the same intellectual potential' (Rancière 1991, p.36).

\section{Summary}

There was what I can only describe as a curling, a need to curl inwards with all things at the same time, curling parallel threads in together, so that they weren't in conflict. So that the subject matter, the voices and stories that I heard and the methodology, remained compatible and held the same ethical stance-all the while thinking about it as two things, the process and the outcomes-both important in the subject matter and the research. The parallels, and inconsistencies that erupted in my research, necessitated considering an ethical method that focuses on reciprocal processes and outcomes. Towards a more inclusive public pedagogy, we need to imagine and write for broader audiences than examiners and the academic world. The knowledge that feeds into research and then out again through research outcomes should take account of the communities who contribute to it. 


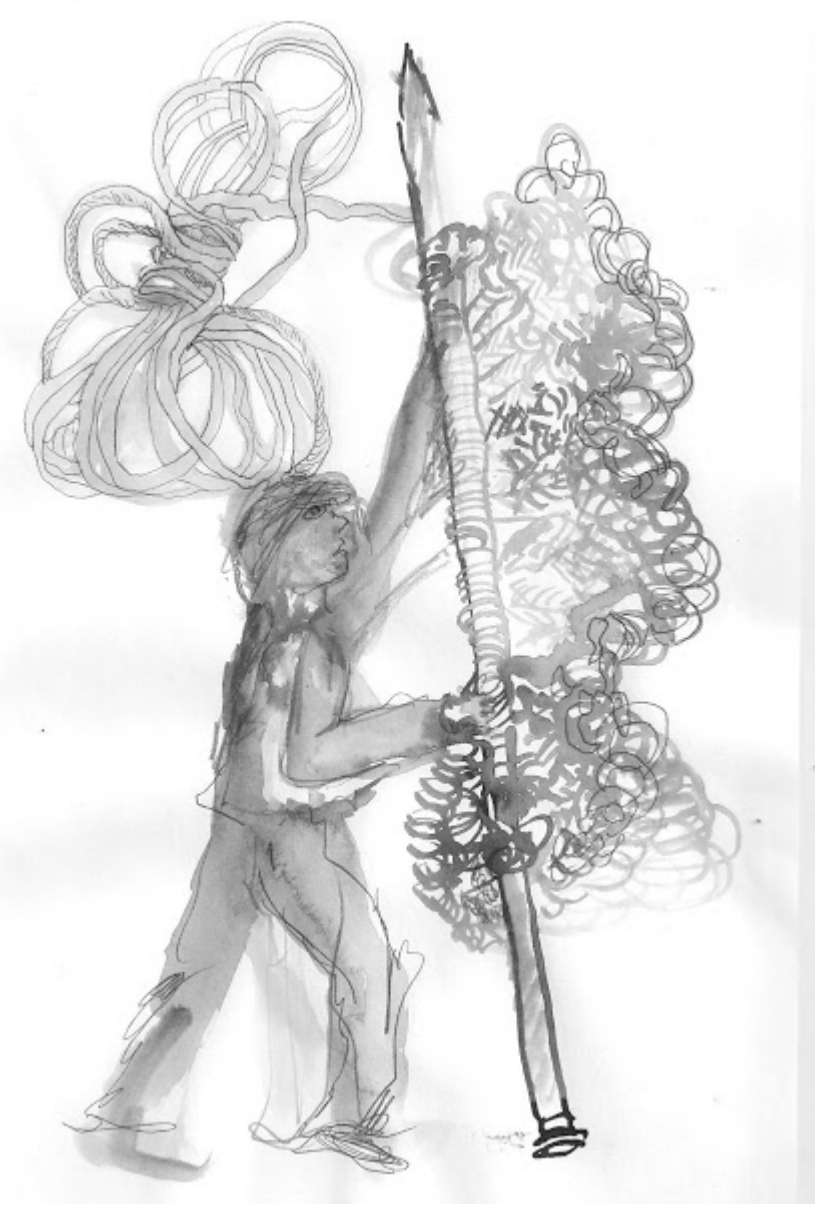

Figure 13: Curled, Debbie Qadri, 2017.

\section{Acknowledgements}

I would like to acknowledge and thank my supervisors at Victoria University, Professor Maureen Ryan and Dr Siew Fang Law, for their support and suggestions in my research and writing this article.

\section{References}

Bacca, J 1995, 'Public art in a many-cultured Society', in Lacy, S (ed.), Mapping the Terrain: New Genre Public Art, Bay Press, Seattle, Washington.

Burdick, J \& Sandlin, J A, 2010, 'Educational Inquiry and the Pedagogical Other: On the Politics and Ethics of Researching Critical Public Pedagogies', in Jennifer Sandlin, Brian Scultz and Jake Burdick (eds.), The Handbook of Public Pedagogy, Routledge, New York.

Deranty, J 2010, Jacques Rancière: Key Concepts, Routledge, New York.

Deutsche, R 1998, Evictions: Art and Spatial Politics, Graham Foundation for Advanced Studies in the Fine Arts, Chicago, Illinois, MIT Press, Cambridge Massachusetts. 
Fine, M., L. Weis, S. Weseen, and L. Wong. 2003. 'For whom? Qualitative Research, Representations, and Social Responsibilities', in Denzin, N and Lincoln, Y (eds.), The Sage Handbook of Qualitative Research, 2nd ed., 107-31. Thousand Oaks, CA: Sage.

Foucault, M 1981, 'The order of Discourse', in Young, R (ed.), Untying the Text: a Post-structuralism Reader, Routledge and Kegan Paul, Boston, London and Henley.

Freshwater, D 2017, 'Perspectives: Reciprocity and Integration in Nursing and Mixed Methods Research', Journal of Research in Nursing, Vol. 22 (4), 328-331.

Hallward, P 2005, 'Jaques Rancière and the Subversion of Mastery', in Robson, Mark (ed.), Jacques Rancière: Aesthetics, Politics, Philosophy, Edinburgh University Press, Edinburgh, U.K.

Harrison, J, MacGibbon, L, Morton, M 2001, 'Regimes of Trustworthiness in Qualitative Research: The Rigors of Reciprocity', Qualitative Inquiry 2001; 7;323, Sage Publications.

Hawkins, G 1993, From Nimbin to Mardi Gras: Constructing Community Arts, Allen and Unwin, St Leonards. NSW, Australia.

Lawrence-Lightfoot, S \& Hoffman Davis, J 1997, The Art and Science of Portraiture, Jossey-Bass, San Francisco, CA.

Leavy, P 2009, Method Meets Art: Arts-Based Research Practice, Guilford Publications, NY.

Keen, S and Todres, L 2007 'Strategies for disseminating Qualitative Research findings: Three Exemplars', Forum: Qualitative Social Research, vol 8, no.3.

Mouffe, C 2008, 'Art and Democracy: Art as an Agonistic Intervention in Public Space', Art as a Public Issue, 14, pp. 6-13.

Michel, T \& Bassinder, J 2013, 'Researching with Reciprocity? Meaningful Participant-based Researching a Remote Indigenous Community Context', proceedings of the 3rd National Local Government Researcher's Forum, 5-6 June 2013, Adelaide, South Australia.

Phillips, P 1995 'Public Constructions', in Lacy, S. (ed.) Mapping the Terrain, Bay Press, Seattle, Washington USA.

Rancière, J 2013, Aisthesis: Scenes from the Aesthetic Regime of Art, translated by Z. Paul, Verso, London

Rancière, J 2011, 'The Thinking of Dissensus: Politics and Aesthetics', in Bowman, P \& Stamp, R (eds.), Reading Rancière, Continuum, London, NY.

Rancière, J 2007, 'The Emancipated Spectator', Artforum International, Vol. 45, Issue 7, March, 2007.

Rancière, J, 1991, The Ignorant Schoolmaster: Five Lessons in Emancipation, translated from French by K. Ross, Stanford University Press, USA.

Rancière, J 2004, The Philosopher and His Poor, translated from the 1983 French original, by Andrew Parker, Duke University, USA.

Ross, K 1991, 'Introduction' in, The Ignorant Schoolmaster: Five Lessons in Emancipation, by Jaques Rancière, translated from French by K. Ross, Stanford University Press, USA. 
Sayers, S 2016, 'Jaques Rancière (2004) 'The Politics of Aesthetics: The Distribution of the Sensible', review, Culture Machine Reviews, http://www.culturemachine.net.

Stevenson, A \& Holloway, J 2016, 'Getting Participants' Voices Heard: using Mobile, Participant Led, Sound-based Methods to Explore Place-making', Area, 2017, 49.1, 85-93 Royal Geographic Society.

Trainor, A \& Bouchard, K 2013, 'Exploring and Developing Reciprocity in Research Design', International Journal of Qualitative Studies in Education, Sep 2013, Vol 26, Issue 8, 986-1003.

Toombs, M 2016, 'The intersection between research and ethics, as it applies to Indigenous methodologies', Aboriginal and Islander Health Worker Journal, Vol. 40, Jan/Dec 2016, 8-10.

Qadri, D 2016, 'What Does Public Art Teach Us? Public Art, Public Pedagogy and Community Participation in Making', Journal of Public Pedagogies, Number 1, 2016, Public Pedagogies Institute, http://www.publicpedagogies.org/journal/ 